\title{
Factors related to drug approvals: predictors of outcome?
}

\section{Lawrence Liberti ${ }^{1,2}$, Alasdair Breckenridge ${ }^{3}$, Jarno Hoekman ${ }^{2,4}$, Neil McAuslane ${ }^{1}$, Pieter Stolk ${ }^{2}$ and Hubert Leufkens ${ }^{2}$}

\footnotetext{
${ }^{1}$ Centre for Innovation in Regulatory Science, 77 Hatton Garden London, EC1N 8JS, UK

${ }^{2}$ Utrecht Institute for Pharmaceutical Sciences, Utrecht University, Universiteitsweg 99, 3584 CG Utrecht, The Netherlands

${ }^{3}$ School of Life Sciences, University of Liverpool, Crown St, Liverpool L69 7ZB, UK

${ }^{4}$ Innovation Studies Group, Copernicus Institute for Sustainable Development, Utrecht University, Heidelberglaan 2, 3584 CS Utrecht, The Netherlands
}

There is growing interest in characterising factors associated with positive regulatory outcomes for drug marketing authorisations. We assessed empirical studies published over the past 15 years seeking to identify predictive factors. Factors were classified to one of four 'factor clusters': evidentiary support; product or indication characteristics; company experience or strategy; social and regulatory factors. We observed a heterogeneous mix of technical factors (e.g., study designs, clinical evidence of efficacy) and less studied social factors (e.g., company-regulator interactions). We confirmed factors known to be of relevance to drug approval decisions (imperative) and a cohort of less understood (compensatory) social factors. Having robust supportive clinical evidence, addressing rare or serious illness, following scientific advice and prior company experience were associated with positive outcomes, which illustrated the multifactorial nature of regulatory decision making and factors need to be considered holistically while having varying, context-dependent importance.

\section{Introduction}

There is growing interest in characterising factors associated with positive regulatory outcomes for drug marketing authorisations. More than 20 years ago, observations that drugs of 'greater importance' (defined by the number of literature and patent citations) were approved with shorter FDA review times suggested that systematic identification of selected factors could provide insights into regulatory outcomes [1]. Since then, a body of work has accumulated seeking to identify factors that provide confidence around a positive regulatory outcome. Concluding that a new drug's benefits outweigh potential risks is a complex multifactorial assessment. This requires the integration and interpretation of a variety of evidence-based technical factors (e.g., study designs, product-related characteristics, clinical evidence of efficacy, safety profile) and social factors

Corresponding author: Liberti, L. (LLiberti@cirsci.org) (e.g., stakeholder expectations, reviewer experience, company experience, company-regulator interactions). Understanding how these and other factors shape the review processes has been recognised as a key factor in expediting patient access to medicines [2]. There is also growing interest in how regulatory science can take a key role to 'evaluate and study regulatory systems in terms of their ability to ensure patient safety, enhance public health and stimulate innovation' [3]. In this tradition, numerous empirical studies have, therefore, sought to analyse factors that contribute to predictability of regulatory success. However, despite more than two decades of research, there is limited understanding of how this research has evolved, what has been learned and what researchers, regulators and policy makers can apply from these observations to more fully characterise a product's benefits and risks to support quality decision making and, ultimately, provide greater predictability around a regulatory outcome. 
Number of articles obtained from initial searches

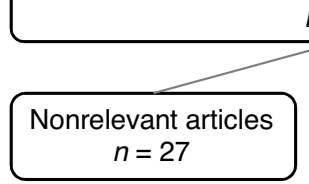
$n=95$

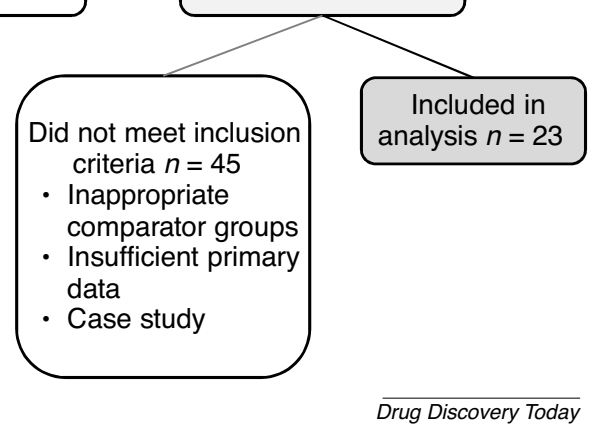

FIGURE 1

Overview of article identification process and article disposition.

The objective of this analysis was to take stock across key empirical research studies conducted in this field to provide insights into the factors that have been most consistently associated with positive and negative regulatory outcomes. We hypothesised that the analysis would confirm the importance of factors widely considered to be of relevance to drug approval decisions and directly associated with demonstration of safety, efficacy and quality per legislative requirements. However, these factors play only a part in the regulatory decision and even after considering these well-characterised factors there is unexplained variance in outcome. The nature and importance of other factors currently remains elusive and studies that have proposed and tested some of these factors have not been reviewed systematically. Although these other decision factors are heterogeneous, understanding their relationship to regulatory outcomes can help companies navigate the complex regulatory decision landscape. The practical relevance of these findings and what opportunities exist for further studies are explored. The methodology that was used for this study is detailed in Box 1 and Table 1.

\section{Observations}

\section{Publication characteristics}

Twenty-three empirical studies were included in the analysis (Fig. 1). These studies were published over a 15-year period (2001-2015). From 2001 to 2009, five articles were published [4-8]. Interest in the topic continued to increase, with six relevant articles being published from 2010 to 2012 [9-14] and 12 articles appearing from 2013 to 2015 [15-26]. The timeframe for which data were analysed in the studies ranged from 1981 to 2014. The majority of studies $(15 ; 65 \%)$ were designed to compare approved and nonapproved (failed or withdrawn) marketing authorisation applications. Six studies assessed approved products only and compared specific cohorts within these (e.g., standard versus accelerated approvals; orphan versus non-orphan); all of these studies were based on FDA approvals. The size of the analysis cohorts varied widely across the studies (20 to 2559 products; median 91 products); 13 (56\%) of studies assessed 100 or fewer medicines.

\section{BOX 1}

\section{Study methodology}

Search strategy

A systematic literature search was performed of PubMed and EmBase databases through 30 November 2015. The starting date was open-ended to identify studies reflecting early research. We conducted Boolean searches using a combination of free text terms: approval/legislation \& jurisprudence; authoris(z)ation; drug approval/methods; drug discovery; drug discovery/trends; medicine regulatory approval; outcome assessment; postmarketing/trends; product surveillance; regulatory success; regulatory outcome. PubMed was also searched using MeSH terms. Additionally, we evaluated the references cited by the identified studies.

We focused our analysis on studies of cohorts of drugs for which a regulatory outcome was reported as the dependent outcome. We included studies that compared a cohort of approved marketing authorisation applications (MAAs) to 'failed' MAAs (not approved or withdrawn from review) or, if based only on a cohort of approved MAAs, the analysis must have compared defined subgroups of MAAs (e.g., orphans versus non-orphans or products that were subject to accelerated, conditional or other special review pathways versus standard approvals). Studies could have been of any design, manuscript type or language; case studies and single-event studies were excluded.

Data extraction

Information on the methodology and outcomes was collected for each study meeting the inclusion criteria: the time range of assessed medicines or marketing authorisations; study objective; study hypothesis; phase of development from which data were derived; sample size and comparison cohorts; geographic region (agency); therapeutic area; approval pathways; statistical methods; whether confounding factors were accounted for; and whether biases or limitations were described.

Factors

For each study, the described factors were identified by the primary author (LL) and verified by an independent reviewer. A study could have described more than one factor and the same factor could have been analysed several ways within the same study (each analysis instance was counted). To evaluate similar factors that were described in source reports using varying descriptions, we developed a common terminology lexicon; each factor was assigned to one of 24 'common factor terms'. To bring continuity to the diversity observed, each common factor term was then classified to one of four 'factor clusters' and the discussion of findings is based on this classification: evidentiary support (e.g., data integrity, study design, number of patients and exposure duration); product or indication characteristics (e. g., dosage form, clinical utility, innovativeness, orphan); company experience or strategy (e.g., size, development strategy, scientific advice, protocol assistance); social and regulatory factors (e.g., regulatory procedures and pathways, advisory committee recommendations) (Table 1). Assignment of common factor terms to factor clusters was guided by the description of factors given in the primary references. Where the primary reference did not provide a description that was consistent with one of our four clusters, the factor was assigned to the most likely cluster by consensus of the authors. For each factor we identified if the authors presented: $P$ value; odds ratio; whether the results derived from a univariate or multivariate analysis and if the factor was associated with a positive or negative regulatory outcome. 
TABLE 1

The assignment of common factor terms to their respective factor clusters

\begin{tabular}{|c|c|}
\hline actor cluster & Common factor terms \\
\hline videntiary support & $\begin{array}{l}\text { Deficient preclinical evidence, support for (or poor evidence of) efficacy, evidence for appropriate dose (dose-effect, PK profile well } \\
\text { established), quantity of data, clinical relevance of study design, endpoint characteristics, endpoint qualification, appropriateness of } \\
\text { number of patients studied, duration of studies, extent of exposure, testing in a representative population, quality of the data, use of a } \\
\text { predictive composite score, safety evidence and concerns }\end{array}$ \\
\hline
\end{tabular}

Product and indication

characteristics

Company experience

and strategy

Social and regulatory

factors
Compound (product) characteristics (physiochemical), indication, well-defined target population, clinical utility, unmet medical need, use for a serious or rare disease, formulation of the dosage form, availability of alternative therapies, innovativeness, disease prevalence, product developed in-house, product acquired or licensed, orphan designation

Prior approvals, company experience, company size, development strategy, clinical development plan, use of protocol assistance, use of scientific advice, adherence to scientific advice, rapidity of completing trials

Regulatory procedures followed, influence of advisory committee recommendations, use of facilitated regulatory pathways (e.g., breakthrough therapy); local healthcare environment or delivery infrastructure; an individual's perception of risks and uncertainties
The results focused primarily on regulatory activities by the European Medicines Agency (EMA) and the FDA, each with ten articles. Two articles assessed products from multiple geographic regions and one focused on Japan. The majority $(17 ; 74 \%)$ of studies analysed medicines from multiple therapeutic categories and six (26\%) focused on oncology products. All but two studies combined multiple approval pathways (e.g., standard, expedited); two specifically compared factors for standard versus expedited approvals.

Whereas all studies described at least one objective, only approximately half $(13 ; 57 \%)$ clearly described a hypothesis in which a specific factor or set of factors were investigated to understand their relationship to regulatory outcome. Hypotheses were widely diverse: five studies sought to support the validity of a specific factor; these assessed factors such as the role of scientific advice, company size, formulation, clinical response. Four sought to identify general learnings from the study of a particular cohort; for example, size of a target population, use of randomised trials or therapeutic innovativeness. Two sought factors that helped with quality decision making; for example, reliance on in-licensed products or rationale for selecting a dosing regimen; and two sought to prove that a prediction tool could be created from a confluence of factors - for example the Approved New Drug Index (ANDI). Because the rationale for conducting studies differed, heterogeneous factors were identified, assessed or described by the authors. For example, when the focus was on production of evidence in the drug development process, evidence-based factors appeared to be more prominent (e.g., number of patients in studies, duration of the studies, response rate) [26], with less focus on non-data-driven social factors (e.g., stakeholder interaction, company experience). Identifying factors was complicated where no clear hypothesis was stated or was difficult to determine (10; 43\%).

All of the analyses were retrospective, with 18 (78\%) of those assessing factors following the submission of the market authorisation dossier. Studies were heterogeneous with regard to the number of factors described and whether the analyses of these factors were univariate or multivariate. Univariate analyses were used in 16 (70\% of studies), multivariate analysis by one $(4 \%)$ and a combination of univariate and multivariate by six (26\%) of the included studies. The majority $(16 ; 70 \%)$ clearly addressed the limitations of the study or specific biases that could have influenced the outcomes. Analysis of the relationship of factors to an outcome can be influenced by confounding factors. However, only eight (35\%) of the studies clearly described a methodology for controlling confounding.

\section{Factor characteristics}

A high degree of heterogeneity was observed for the factors associated with a regulatory outcome. Overall, 151 instances of factors were identified across the 23 studies and were categorised by their common factor terms to one of four factor clusters (see supplementary material online). The most common factor cluster was evidentiary support $(52 ; 34 \%)$ followed by company experience or strategy $(46 ; 31 \%)$, product and indication characteristics (45; $30 \%$ ), and social and regulatory factors (8; 5\%) (Fig. 2).

The most common factors observed (Table 2) that related to a positive outcome were: having supportive efficacy evidence (17); having a product that will treat a serious or rare disease or meets unmet medical need (12); that scientific advice given by regulators was followed (11); and that the company had prior experience with the therapeutic area or a history of prior approvals (10). The factors observed to be most commonly related to a negative regulatory outcome were having poor evidence of efficacy (6) and deficiencies in the clinical plan methodology (5).

Odds ratios were presented by the authors to characterise the strength of approximately half $(77 ; 51 \%)$ of factors. Overall, 66 of 151 (44\%) factors were reported to be significantly $(P<0.05)$ related to an outcome. We evaluated the number of statistically significant factors by cluster, for those factors observed in two or more studies. Two clusters (the lack of company experience or strategy and complications with product indications or characteristics) had factors that were most often statistically significantly associated with a negative outcome. The heterogeneity of factors was further confirmed in that none of the factor clusters showed a trend towards more occurrences in studies over time nor was there a trend towards a consensus around particular clusters over time. No study assessed whether the same factors were more influential during early stages versus later stages of development. Table 3 summarises the main characteristics and common factor terms identified in each study. The 151 factors were categorised according to 24 common factor terms (Tables 1 and 2). The majority $(115 ; 76 \%)$ were positively related to product approval and 36 (24\%) were negatively associated.

(1)




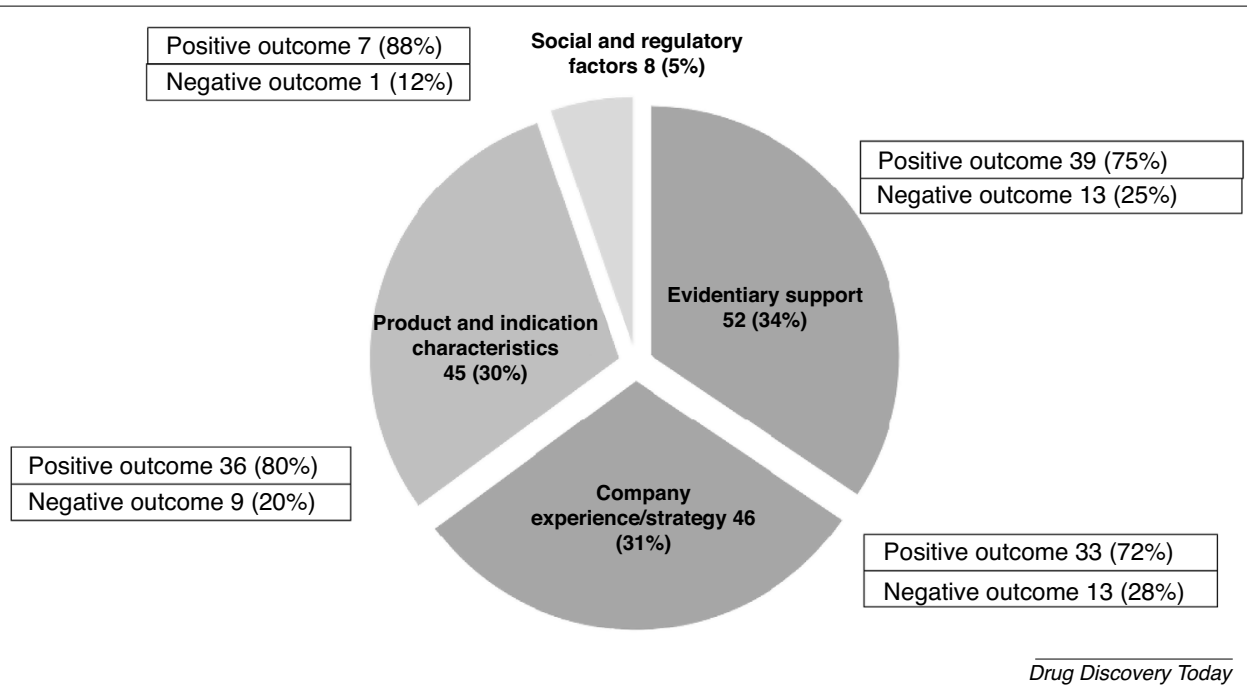

\section{FIGURE 2}

Categorising factors by factor cluster illustrates the divergence in characteristics studied and the observed emphasis on factors associated with a positive regulatory outcome ( $n=151$ factors).

TABLE 2

Understanding the frequency of observations of common factor terms and factor clusters and their relationship to regulatory outcomes

\section{Factor cluster ${ }^{\mathbf{a}}$}

Common factor term

Supportive efficacy evidence

Serious and/or rare disease; unmet medical need

Prior approval or company experience

Scientific advice (adherence or nonadherence)

Company size and sales (large vs mid-size or small)

Indication factors (well-defined target indication)

Compound factors (quality, etc.)

Clinical development plan methodology

Patient numbers (use of appropriate numbers for the indication)

Endpoints (use of qualified endpoints)

Poor evidence of efficacy

Facilitated regulatory pathways (use novel pathways)

Advisory committee recommendation (outcomes)

Dose evidence (having substantial dose-effect and pharmacokinetic data)

Formulation (oral vs non-oral)

Study design (clinical relevance)

Compound source (initial discovery company; in-licensed)

Innovativeness (novelty of the therapeutic approach)

Data quality (poor quality leads to failure)

Deficient preclinical plan or evidence (leads to failure)

Composite score (a score aggregating several factors)

Disease prevalence (understanding the target population)

Safety concerns (detrimental to the benefit:risk profile)

Trial duration (of appropriate length)

${ }^{\mathrm{a} A}$

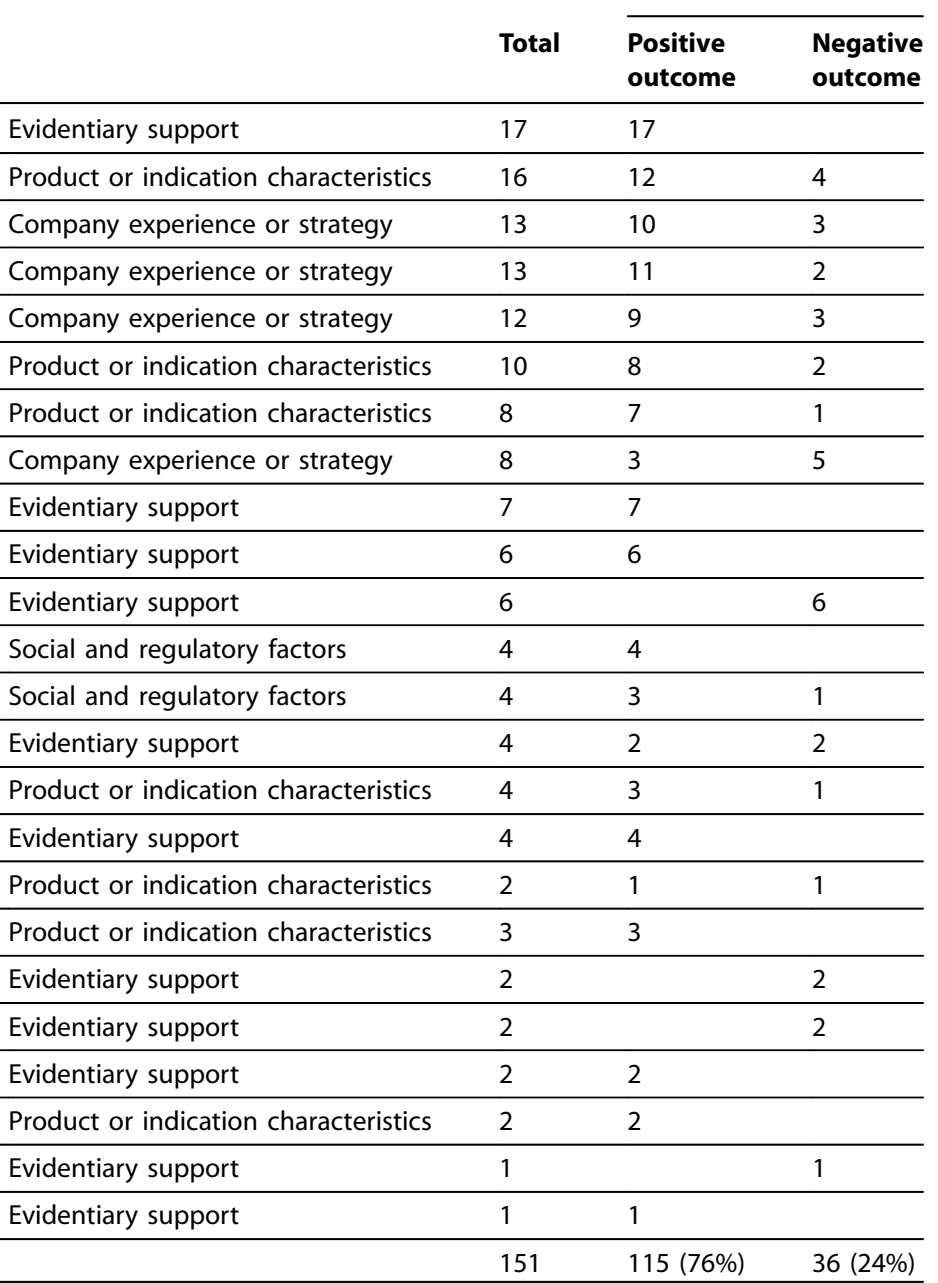

common factor term could have been categorised into one or more factor clusters, but for this analysis each was accounted for in only one factor cluster. 
TABLE 3

\begin{tabular}{|c|c|c|c|c|c|}
\hline \multicolumn{6}{|c|}{ A summary of the objectives, key characteristics and factors identified by the assessed studies } \\
\hline Refs & $\begin{array}{l}\text { Year of } \\
\text { publication }\end{array}$ & Objectives & $\begin{array}{l}\text { Sample } \\
\text { size }\end{array}$ & $\begin{array}{l}\text { Univariate or } \\
\text { multivariate } \\
\text { analysis }\end{array}$ & $\begin{array}{l}\text { Factors identified }^{\mathrm{a}} \\
\text { (by common factor terms) }\end{array}$ \\
\hline [4] & 2001 & To analyse success rates for NCEs & 671 & Univariate & Clinical plan methodology \\
\hline [5] & 2002 & $\begin{array}{l}\text { To study the issues raised during MAA review and } \\
\text { to identify predictors of outcome }\end{array}$ & 111 & $\begin{array}{l}\text { Univariate and } \\
\text { multivariate }\end{array}$ & $\begin{array}{l}\text { Clinical plan methodology } \\
\text { Compound characteristics } \\
\text { Deficient preclinical plan } \\
\text { Poor evidence of efficacy }\end{array}$ \\
\hline [6] & 2006 & $\begin{array}{l}\text { To determine whether therapeutic innovation } \\
\text { prevails among nonbiotechnological products }\end{array}$ & 251 & Univariate & $\begin{array}{l}\text { Innovativeness } \\
\text { Rare and serious disease; } \\
\text { unmet medical need }\end{array}$ \\
\hline [7] & 2008 & $\begin{array}{l}\text { To identify predictors of successful marketing } \\
\text { authorisation for OMPs }\end{array}$ & 91 & $\begin{array}{l}\text { Univariate and } \\
\text { multivariate }\end{array}$ & $\begin{array}{l}\text { Company size and sales } \\
\text { Compound characteristics } \\
\text { Disease prevalence } \\
\text { Formulation } \\
\text { Indication characteristic } \\
\text { Innovativeness } \\
\text { Prior approval and experience } \\
\text { Rare and serious disease; } \\
\text { unmet medical need }\end{array}$ \\
\hline [8] & 2009 & $\begin{array}{l}\text { To determine whether AA for oncology drugs } \\
\text { facilitates rapid access; whether confirmatory trials } \\
\text { are completed; whether safety concerns are } \\
\text { identified after AA is granted }\end{array}$ & 51 & Univariate & $\begin{array}{l}\text { FRPs } \\
\text { Patient numbers } \\
\text { Supportive efficacy evidence }\end{array}$ \\
\hline [9] & 2010 & $\begin{array}{l}\text { To assess factors associated with clinical approval } \\
\text { success rates and clinical development phase } \\
\text { transitions }\end{array}$ & 2,559 & Univariate & $\begin{array}{l}\text { Compound characteristics } \\
\text { Compound source } \\
\text { Indication characteristic }\end{array}$ \\
\hline [10] & 2010 & $\begin{array}{l}\text { To identify factors associated with the outcomes of } \\
\text { MAAs (with focus on scientific advice) }\end{array}$ & 188 & $\begin{array}{l}\text { Univariate and } \\
\text { multivariate }\end{array}$ & $\begin{array}{l}\text { Company size and sales } \\
\text { Rare and serious disease; } \\
\text { unmet medical need } \\
\text { Scientific advice }\end{array}$ \\
\hline [11] & 2011 & $\begin{array}{l}\text { To determine crucial factors related to failure to } \\
\text { achieve marketing authorisation for OMPs }\end{array}$ & 56 & Univariate & $\begin{array}{l}\text { Company size and sales } \\
\text { Compound characteristics } \\
\text { Data quality } \\
\text { Formulation } \\
\text { Poor evidence of efficacy } \\
\text { Prior approval and experience } \\
\text { Rare and serious disease; } \\
\text { unmet medical need } \\
\text { Scientific advice }\end{array}$ \\
\hline$[12]$ & 2011 & $\begin{array}{l}\text { To define characteristics of approved OMP cancer } \\
\text { drugs and their pivotal clinical trials versus non- } \\
\text { OMPs }\end{array}$ & 27 & Univariate & $\begin{array}{l}\text { Advisory committee recommendation } \\
\text { Endpoints } \\
\text { Patient numbers } \\
\text { Study design }\end{array}$ \\
\hline [13] & 2012 & $\begin{array}{l}\text { To investigate underlying factors of nonapproved } \\
\text { NCEs }\end{array}$ & 68 & Multivariate & $\begin{array}{l}\text { Clinical plan methodology } \\
\text { Poor evidence of efficacy } \\
\text { Supportive efficacy evidence }\end{array}$ \\
\hline$[14]$ & 2012 & To assess determinants of successful MAA for OMPs & 114 & $\begin{array}{l}\text { Univariate and } \\
\text { multivariate }\end{array}$ & $\begin{array}{l}\text { Company size and sales } \\
\text { Compound characteristics } \\
\text { Dose evidence } \\
\text { Endpoints } \\
\text { Indication characteristic } \\
\text { Prior approval and experience } \\
\text { Rare and serious disease; } \\
\text { unmet medical need } \\
\text { Scientific advice } \\
\text { Study design } \\
\text { Supportive efficacy evidence }\end{array}$ \\
\hline [15] & 2013 & $\begin{array}{l}\text { To assess reasons for failure of NCEs to gain } \\
\text { regulatory approval }\end{array}$ & 53 & Univariate & $\begin{array}{l}\text { Data quality } \\
\text { Dose evidence }\end{array}$ \\
\hline
\end{tabular}


TABLE 3 (Continued)

\begin{tabular}{|c|c|c|c|c|c|}
\hline$\overline{\text { Refs }}$ & $\begin{array}{l}\text { Year of } \\
\text { publication }\end{array}$ & Objectives & $\begin{array}{l}\text { Sample } \\
\text { size }\end{array}$ & $\begin{array}{l}\text { Univariate or } \\
\text { multivariate } \\
\text { analysis }\end{array}$ & $\begin{array}{l}\text { Factors identified }^{\mathrm{a}} \\
\text { (by common factor terms) }^{\text {(by }}\end{array}$ \\
\hline [16] & 2013 & $\begin{array}{l}\text { To determine whether characteristics of } \\
\text { nonapproved NCEs predict the likelihood of } \\
\text { approval in subsequent review rounds }\end{array}$ & 52 & Univariate & $\begin{array}{l}\text { Advisory committee recommendation } \\
\text { Company size and sales } \\
\text { FRPs } \\
\text { Indication characteristic } \\
\text { Poor evidence of efficacy } \\
\text { Safety concerns }\end{array}$ \\
\hline [17] & 2013 & $\begin{array}{l}\text { To estimate for oncology NCEs the impact of } \\
\text { regulatory decision-making on attrition rates; to } \\
\text { identify determinants of successful outcomes }\end{array}$ & 46 & Univariate & $\begin{array}{l}\text { Compound characteristics } \\
\text { Endpoints } \\
\text { Rare and serious disease; } \\
\text { unmet medical need }\end{array}$ \\
\hline [18] & 2013 & $\begin{array}{l}\text { To build an algorithm for a probability of approval } \\
\text { for oncology drugs that have completed Phase II }\end{array}$ & 61 & $\begin{array}{l}\text { Univariate and } \\
\text { multivariate }\end{array}$ & $\begin{array}{l}\text { Clinical plan methodology } \\
\text { Composite score } \\
\text { Patient numbers } \\
\text { Rare and serious disease; } \\
\text { unmet medical need } \\
\text { Supportive efficacy evidence }\end{array}$ \\
\hline [19] & 2014 & $\begin{array}{l}\text { To assess development times, clinical testing, post- } \\
\text { market follow-up and safety risks for approved } \\
\text { NCEs }\end{array}$ & 20 & Univariate & $\begin{array}{l}\text { FRPs } \\
\text { Patient numbers }\end{array}$ \\
\hline [20] & 2014 & $\begin{array}{l}\text { To identify characteristics and outcomes of } \\
\text { published Phase I studies associated with } \\
\text { regulatory approval }\end{array}$ & 88 & Univariate & $\begin{array}{l}\text { Patient numbers } \\
\text { Supportive efficacy evidence }\end{array}$ \\
\hline [21] & 2014 & $\begin{array}{l}\text { To investigate whether self-originated NCEs } \\
\text { differed from acquired NCEs regarding MAA } \\
\text { outcomes }\end{array}$ & 171 & Univariate & $\begin{array}{l}\text { Company size and sales } \\
\text { Compound source }\end{array}$ \\
\hline$[22]$ & 2014 & $\begin{array}{l}\text { To describe the organisation and function of } \\
\text { advisory committees }\end{array}$ & 214 & Univariate & $\begin{array}{l}\text { Advisory committee } \\
\text { recommendation }\end{array}$ \\
\hline [23] & 2015 & $\begin{array}{l}\text { To assess factors associated with the sustainability } \\
\text { of drug development }\end{array}$ & 257 & Univariate & FRPs \\
\hline [24] & 2015 & $\begin{array}{l}\text { To explore the relationship of three endpoints used } \\
\text { in MAAs to regulatory outcomes for oncology } \\
\text { products }\end{array}$ & 50 & Univariate & $\begin{array}{l}\text { Endpoints } \\
\text { Supportive efficacy evidence }\end{array}$ \\
\hline$[25]$ & 2015 & $\begin{array}{l}\text { To investigate whether SA leads to changes in } \\
\text { clinical trial design and whether the timing of and } \\
\text { compliance with SA affects regulatory assessment } \\
\text { and outcome }\end{array}$ & 232 & Univariate & Scientific advice \\
\hline$[26]$ & 2015 & $\begin{array}{l}\text { To build an algorithm that assigns a probability of } \\
\text { regulatory approval to oncology drugs that have } \\
\text { completed Phase II testing and to compare the } \\
\text { ease of use and accuracy of various predictive } \\
\text { modelling technique }\end{array}$ & 98 & $\begin{array}{l}\text { Univariate and } \\
\text { multivariate }\end{array}$ & $\begin{array}{l}\text { Company size and sales } \\
\text { Composite score } \\
\text { Formulation } \\
\text { Patient numbers } \\
\text { Rare and serious disease; } \\
\text { unmet medical need } \\
\text { Supportive efficacy evidence } \\
\text { Trial duration }\end{array}$ \\
\hline
\end{tabular}

Abbreviation: AA, accelerated approval; FRP, facilitated regulatory pathway; MAA, marketing authorisation application; NCE, new chemical entity; OMP, orphan medicinal product; SA, scientific advice (from regulators).

${ }^{a}$ A common factor term can encompass multiple individual factors observed in a study.

\section{Discussion}

We assessed a diverse group of empirical studies that aimed to elucidate factors related to regulatory outcomes. We observed that the studies identified a broad mix of heterogeneous factors confirming numerous recognised 'imperative' factors that point towards regulatory success; but, importantly, our observations contribute to this heterogeneous research field by elucidating less recognised 'compensatory' factors. These observations provide holistic evidence of the important nature of compensatory factors, which are less well characterised yet are often crucial determinants. This is in line with our premise that, despite more than two decades of research and the identification of primarily imperative factors, few studies have focused on the contribution of other factors based on an overview of the findings. We found that nondata-driven social factors often play a compensatory part yet can influence the predictability of the outcome of a product's review. Based on these observations we conclude that no factor or cluster of factors alone provides the reason for submission success or failure; because of their heterogeneity, factors cannot be applied in isolation to an outcome but need to be considered holistically in relation to other factors that carry varying, context-dependent importance. The four factor clusters we used to organise factors are 
consistent with real-world regulatory outcomes as illustrated by the following examples derived from product approvals and failures described in European Public Assessment Reports and withdrawal assessment reports. Our discussion focuses on key findings within each factor cluster.

\section{Evidentiary support}

Having robust, supportive evidence of a clinical effect was the most common factor associated with a positive outcome; conversely, poor evidence of efficacy was the most common factor associated with a negative outcome. The FDA (http://www.fda. gov/downloads/Drugs/GuidanceCompliance\%20Regulatory Information/Guidances/UCM078749.pdf) [27] and EMA (http:// www.ema.europa.eu/docs/en_GB/document_library/Scientific_ guideline/2011/12/WC500119966.pdf) [28] have provided guidance around standards for demonstrating efficacy of drug and biologics including oncology products. These guidance reports enabled sponsors to plan drug development programmes to be sufficiently robust to establish effectiveness without being excessive in scope and to bring greater consistency and predictability to the agencies' assessment of efficacy. Importantly, following evidentiary guidelines has been linked with positive regulatory outcomes [24].

The product Giotrif ${ }^{\mathbb{R}}$ (afatinib) is an example of the association of quality evidence derived from well-designed studies and a positive regulatory outcome. This product was granted marketing authorisation by the EMA for non-small-cell lung cancer (NSCLC) with activating epidermal growth factor receptor (EGFR) mutations. The recommendation for approval was based on a favourable benefit:risk profile supported by a progression-free survival (PFS) of 11.1 months $(P<0.001$ compared with alternative treatment) and an overall survival (OS) of 16.2 months (nonsignificant). The product was assessed using a broad range of endpoints: one hard endpoint (OS) and six surrogate endpoints. The reviewers concluded that 'the magnitude of the benefit in terms of PFS demonstrated for afatinib over chemotherapy in treatment-naive patients is statistically significant and clinically meaningful. In addition, benefit was also shown in terms of symptom control. These data are considered robust' [29]. The magnitude of improvement, the statistical significance and the diversity of endpoints have been shown to be predictors of positive regulatory outcomes for oncology products [24].

By contrast, poor study design resulted in weak clinical evidence, which led to a major objection to the Erbitux ${ }^{\circledR}$ (cetuximab) EMA marketing application, wherein the sponsor was seeking an extension of indication in combination with platinum-based chemotherapy for the first-line treatment of patients with advanced or metastatic NSCLC with high EGFR expression. Although the reviewers considered the endpoint (EGFR immunohistochemistry score) as a reliable predictive factor, the cut-off used by the sponsor was found to be in need of further validation. For this application, the lack of supportive efficacy evidence complicated by a poorly defined endpoint [30] were consistent with our observations, pointing to the likelihood of a failed regulatory outcome.

\section{Product or indication characteristics}

The studies in this cohort observed that having a therapy that addresses a serious or rare disease or which meets an unmet medical need has been associated with positive regulatory outcomes. Demonstrating robust product quality was associated with positive outcomes; conversely, poor product quality can lead to a negative outcome (Table 2) despite the product being developed for a high unmet medical need. In 2014, the initial marketing application to the EMA for faldaprevir for hepatitis $\mathrm{C}$ was withdrawn by the sponsor (Boehringer Ingelheim). At withdrawal, the Committee for Medicinal Products for Human Use (CHMP) was of the provisional opinion that the drug could not be approved because of 'concerns regarding the starting materials used for the manufacture of the active substance and a problematic dissolution profile'. Therefore, despite being developed for a serious illness, owing to the concerns about quality the benefits of faldaprevir did not outweigh its risks.

\section{Social and regulatory factors}

The field of factor assessment has evolved based on studies largely focused on readily measurable, historically observable, evidencebased factors and less so on social (non-data-driven) factors. Although being difficult to quantify, social factors probably have an important role in characterising products wherein efficacy could be marginal or hard to measure, for which the safety profile is troublesome or the place in therapy is unclear [31,32]. These were the least-studied factors in our cohort. More attention, therefore, needs to be given to these contextual and non-datadriven social factors.

Several studies have begun to investigate the role of social factors in regulatory decision making. Regulators who participated in a 'discrete choice survey' [33] to assess the benefits and risks associated with a hypothetical oral hypoglycaemic agent were found to value the major benefits and risks for an individual patient with diabetes similarly to a comparative cohort of doctors and patients; nevertheless, they exhibited some differences regarding the value of minor or short-term drug effects. Although this study did not support the assumption that regulators have fundamentally different views from other stakeholders when valuing individual drug benefits and risks, it illustrated that differences can exist regarding the relative value of specific effects. In line with these observations, a survey of FDA and EMA reviewers [34] recognised that, although evidence-based factors were the main drivers of most regulatory decisions, social factors (e.g., interactions with the industry, with clinical opinion leaders and patients) can contribute to divergent decisions observed between the agencies. Similarly, how European medical assessors perceive the benefits and risks of medicines has been related to social factors such as personality traits (e.g., how extraverted assessors perceived themselves) and gender [35]. More work is required in this field.

The use of novel accelerated pathways was associated with positive outcomes (four instances; Table 2), probably because these are often used for therapies for serious illnesses with unmet medical needs. In 2015, 61\% of new active substances approved by the FDA benefitted from at least one of the available facilitated regulatory pathways to expedite the regulatory process, as did $47 \%$ at the Japanese Pharmaceuticals and Medical Devices Agency (PMDA), 44\% at Swissmedic, 33\% at Health Canada and $32 \%$ at the EMA; the extent to which social factors play a part in these accelerated pathways should be studied 
further (http://www.cirsci.org/wp-content/uploads/2016/05/ CIRS_RD_-Briefing_59_23052016.pdf) [36].

\section{Company experience or strategy}

We observed several factors within this cluster that were associated with positive outcomes (e.g., having a prior approval and company experience, adhering to regulatory scientific advice, being a wellresourced company and having a robust clinical development plan). In July 2016, the novel agent Begedina ${ }^{\circledR}$ (begelomab) was reviewed for a proposed use in the treatment of acute graft-versushost disease. The negative opinion for this product was representative of the multifactorial nature of regulatory decisions. Importantly, the CHMP found that the clinical data provided were 'insufficient to demonstrate a beneficial effect of Begedina ${ }^{\mathbb{R}}$, and that 'the safety profile and the way the medicine was expected to work had not been sufficiently characterised'. The CHMP also noted there were 'deficiencies identified in the manufacturing process of the medicine' (http://www.ema.europa.eu/docs/ en_GB/document_library/Medicine_QA/2016/07/WC500210883. pdf) [37]. The sponsor withdrew the application. This product was developed by Adienne - a small-to-medium enterprise, Swiss-based private company. At the time, the company had one approved drug.

Our study observed documented contributing factors associated with the negative decision for Begedina ${ }^{\mathbb{R}}$ MAA: deficient preclinical plans that did not completely characterise the mechanism-ofaction, poor supportive clinical evidence, quality (manufacturing) issues, small company size, a focus on rare diseases and a limited number of prior approvals. This recent failed application indicates that recognising a priori the multiple factors also identified in our review would probably have provided directional evidence that this MAA could have met with an unfavourable outcome.

\section{Are some factors more important than others?}

Experienced medicine developers and regulators could point to some of the factors as intuitively obvious: strong supportive evidence, adhering to scientific advice. But the cases illustrated herein indicate that, although the scientific evidence (e.g., the technical factors) provides an initial assessment basis, other factors tip the scale for or against a positive outcome. The impact of these intuitive, imperative factors (which are typically technical factors that appear as obvious to some) is therefore influenced and balanced by compensatory factors that have a balancing role (those addressing an unmet medical need, company experience, strength of the clinical plan methodology). Compensatory factors are often crucial in changing how a positive benefit:risk balance is reached (e.g., demonstration and valuation of unmet medical needs, receiving and adhering to advice, procedural characteristics when there is considerable ambiguity about the strength of evidence between different experts and stakeholder groups and regulatory status such as orphan designation or fast track). For a particular decision, therefore, compensatory factors could play a most crucial part, particularly in difficult regulatory decisions.

An example of the multifactorial complexity of regulatory decision making can be seen in the evaluation of a medicine to address the challenge of malignant ascites wherein clinicians are faced with limited treatment options. In 2009, the EMA approved Removab (R) (catumaxomab) for use in patients with
EpCAM-positive carcinomas where other treatments had failed. Despite a non-statistically-significant increase in puncture-free survival versus paracentesis (from 11 days to 46 days), the occurrence of significant but manageable adverse events and the need for hospitalisation, the CHMP reached a favourable conclusion regarding the product's risk:benefit balance. The intuitive imperative factors would have suggested a negative opinion for this product. Numerous compensatory factors, therefore, appear to have contributed to the outcome more heavily than the limited evidence-based technical factors. These probably included factors such as the size and experience of the sponsor company (Fresenius Biotech - a part of Fresenius with 2015 sales of $€ 27.6$ billion), a factor identified by van den Bogert et al. [21], and that the sponsor took scientific advice on multiple occasions from the EMA regarding clinical aspects of the dossier and that most clinical studies were completed rapidly despite recruiting difficulties. These multiple factors associated with a positive outcome are consistent with factors in studies evaluated herein.

\section{Opportunities for further study}

None of the studies in our analysis assessed how stakeholders weighted or valued particular factors within the context of a product-specific decision, thereby providing an important opportunity for new research. Decision frameworks can help to more explicitly describe the value and relative importance of particular imperative and compensatory factors to the development of an innovative new medicine and to the associated regulatory decision [38]. Frameworks that document and contextualise the value of these factors could help to understand the basis for consistent or divergent decisions among regulatory agencies and individual regulators $[34,39]$. These divergences might seem idiosyncratic but describing the extent to which various factors are weighted to achieve the decision can provide transparency around the relative contribution of these factors [40].

Some factors can serve as proxies for other influencers and might not be directly brought into the individual decision-making process. These are often higher-level associations established on a population level (when comparing groups of drugs). These associations point to abilities, prior experiences, extent of standardization, among others. For example, although several studies observed that larger company size was associated with a positive regulatory outcome, it is likely that sales or R\&D volume alone were not the drivers of success. That these larger companies probably had greater financial resources to invest, could have had staff with more years and diversity of backgrounds, and more years of submission experience in a disease area, might have been factors underlying the aggregate 'large company size' factor. These also had the ability to establish robust evidence and to navigate the complex regulatory landscape. Our findings indicate that future work should focus on the role and added value of novel, indirect and compensatory social factors. It is clear that current development best practices need to address the confluence of regulatory and access requirements. Although none of the studies in this cohort identified factors associated with positive market access recommendations, it is likely that factors such as scientific advice, robustness of the clinical programme, the endpoints used, strength of the efficacy data and the target indication can all play a part in pointing towards positive access. 
Our overall observations are directionally consistent with the consensus recommendations on regulatory predictability derived from two international workshops [2]; these identified a variety of key factors during product development that could contribute to predictability of a regulatory outcome: having agreed-upon surrogates and biomarkers; using clinically relevant dosages and forms; using regulatory validated assessment tools; having constructive interactions with regulators; selecting appropriate comparators; developing a realistic benefit:risk profile; and demonstrating that the product can be clearly differentiated from other therapies and can address an unmet medical need. Taken individually, some factors could potentially serve as predictors of regulatory outcome. But, as observed from the above cases, these factors need to be assessed in a multidimensional milieu which has made it difficult to capture with simple metrics their individual value to a regulatory decision. Because of the heterogeneity we observed across these studies, the almost infinite permutations of factors indicates the need for a new, holistic approach to understanding the relative contribution of data-driven and social factors to development and regulatory decisions. Furthermore, because in some cases values are the crucial influencers in decision-making, the question 'what kinds of data are important?' might be better stated as 'whose opinion regarding these data is valued?' This supports a 'procedural adjustment' making regulatory assessments increasingly open to input from a wider range of stakeholders such as patients, healthcare professionals and health technology assessors. Because of the multifactorial nature of these decisions, future research should assess the contribution of factors using multivariate models, as some of the studies in this cohort have. Our findings point towards the use of new comprehensive datasets and novel analytical techniques such as using machine learning for text mining and pattern recognition to provide more clearly defined factors that play a part in complex regulatory decisions. The integrated analysis of large public, private or consortium research and regulatory outcomes databases could offer novel regulatory science insights that can foster successful innovation and a more predictable regulatory process.

\section{Concluding remarks}

The variety of study designs and analytical techniques, viewpoints and mixed hypotheses described in empirical studies to date have produced a heterogeneous mix of factors, with diversity across studies. Based on decades of individual reports, we confirmed a group of data-driven technical factors, today recognised as imperative, intuitive and self-evident, as the basis for regulatory decisions. However, we found that non-data-driven social factors that often served as compensatory factors play an important contributory part in determining the outcome of a product's review especially in cases where the benefit:risk profile is complex.

Based on these observations, we conclude that no factor or cluster of factors alone provides the reason for submission success or failure but needs to be considered holistically recognising that they carry varying, context-dependent importance. Drug developers who are not already working to identify the contribution of various factors to their product's probability of outcome profile in a dynamic way over time should incorporate such findings into their decision-making processes. More-detailed holistic analyses of factors observed in this study could provide evidence to further enhance predictability of the regulatory outcome.

\section{Acknowledgements}

The authors wish to thank Joseph Scheeren (Senior Vice President, Head Regulatory Affairs for Pharma \& Consumer Health, Bayer) for his advice on this manuscript and Magda Bujar (Senior Analyst, CIRS) for assistance in auditing portions of this dataset.

\section{Supplemental Information}

Supplementary Information associated with this article can be found, in the online version, at http://dx.doi.org/10.1016/j. drudis.2017.03.003.

\section{References}

1 Dranove, D. and Meltzer, D. (1994) Do important drugs reach the market sooner? RAND J. Econ. 25, 402-423

2 Liberti, L. et al. (2010) Expediting patients' access to medicines by improving the predictability of drug development and the regulatory approval process. Clin

Pharmacol. Ther. 87, 27-31

3 Schellekens, H. et al. (2011) Drug regulatory systems must foster innovation. Science $332,174-175$

4 DiMasi, J.A. (2001) Risks in new drug development: approval success rates for investigational drugs. Clin. Pharmacol. Ther. 69, 297-307

5 Pignatti, F. et al. (2002) The review of drug applications submitted to the European Medicines Evaluation Agency: frequently raised objections, and outcome. Eur. J. Clin. Pharmacol. 58, 573-580

6 Motola, D. et al. (2006) An update on the first decade of the European centralized procedure: how many innovative drugs? Br. J. Clin. Pharmacol. 62, 610-616

7 Heemstra, H.E. et al. (2008) Predictors of orphan drug approval in the European Union. Eur. J. Clin. Pharmacol. 64, 545-552

8 Richey, E.A. et al. (2009) Accelerated approval of cancer drugs: improved access to therapeutic breakthroughs or early release of unsafe and ineffective drugs? J. Clin. Oncol. 27, 4398-4405

9 DiMasi, J.A. et al. (2010) Trends in risks associated with new drug development: success rates for investigational drugs. Clin. Pharmacol. Ther. 87, 272-277

10 Regnstrom, J. et al. (2010) Factors associated with success of market authorisation applications for pharmaceutical drugs submitted to the European Medicines Agency. Eur. J. Clin. Pharmacol. 66, 39-48

11 Heemstra, H.E. et al. (2011) Characteristics of orphan drug applications that fail to achieve marketing approval in the USA. Drug Discov. Today 16, 73-80

12 Kesselheim, A.S. et al. (2011) Characteristics of clinical trials to support approval of orphan vs nonorphan drugs for cancer. JAMA 305, 2320-2326

13 Putzeist, M. et al. (2012) Factors influencing non-approval of new drugs in Europe. Nat. Rev. Drug Discov. 11, 903-904

14 Putzeist, M. et al. (2012) Determinants for successful marketing authorisation of orphan medicinal products in the EU. Drug Discov. Today 17, 352-358

15 Asada, R. et al. (2013) Analysis of new drugs whose clinical development and regulatory approval were hampered during their introduction in Japan. J. Clin. Pharm. Ther. 38, 309-313

16 Wang, B. et al. (2013) Clinical and regulatory features of drugs not initially approved by the FDA. Clin. Pharmacol. Ther. 94, 670-677

17 Hartmann, M.C. et al. (2013) Approval probabilities and regulatory review patterns for anticancer drugs in the European Union. Crit. Rev. Oncol. Hematol. 87, 112-121

18 Getz, K. and Kaitlin, K. (2013) A new tool for predicting marketing approval of oncology drugs. Tufts Center for the Study of Drug Development R\&D Leadership Brief Available at: http://csdd.tufts.edu/files/uploads/ CSDD-Janssen_Oncology_Predictive_Tool.pdf

19 Moore, T.J. and Furberg, C.D. (2014) Development times, clinical testing, postmarket follow-up, and safety risks for the new drugs approved by the US Food and Drug Administration: the class of 2008. JAMA Intern. Med. 174, 90-95

20 Malik, L. et al. (2014) Predicting success in regulatory approval from Phase I results. Cancer Chemother. Pharmacol. 74, 1099-10103 
21 van den Bogert, C.A. et al. (2014) Regulatory watch: outcomes of EMA marketing authorization applications: does partnering have an influence? Nat. Rev. Drug. Discov. 13, 878

22 Ciociola, A.A. et al. (2014) The Food and Drug Administration advisory committee and panels: how they are applied to the drug regulatory process. Am. J. Gastroenterol. 109, 1508-1512

23 Belleli, R. et al. (2015) Regulatory watch: efficiency indicators for new drugs approved by the FDA from 2003 to 2013. Nat. Rev. Drug Discov. 14, 156

24 Liberti, L. et al. (2015) Observations on three endpoint properties and their relationship to regulatory outcomes of European oncology marketing applications. Oncologist 20, 683-691

25 Hofer, M.P. et al. (2015) Regulatory watch: impact of scientific advice from the European Medicines Agency. Nat. Rev. Drug Discov. 14, 302-303

26 DiMasi, J.A. et al. (2015) A tool for predicting regulatory approval after phase II testing of new oncology compounds. Clin. Pharmacol. Ther. 98, 506-513

27 US Food and Drug Administration (1988) Guidance for industry providing clinical evidence of effectiveness for human drug and biological products.

28 European Medicines Agency Oncology Working Party (2014) Guideline on the evaluation of anticancer medicinal products in man.

29 Committee for Medicinal Products for Human Use (CHMP) European Medicines Agency (2013) CHMP assessment report. Giotrif (Afatinib). EMA/491185/2013.

30 Committee for Medicinal Products for Human Use (CHMP) European Medicines Agency (2012) CHMP withdrawal assessment report, Erbitux (cetuximab) EMA/ CHMP/628005/2012.

31 McIntyre, T.D. et al. (2012) How FDA advisory committee members prepare and what influences them. Ther. Innov. Reg. Sci. 47, 32-40
32 Marangi, M. et al. (2014) Insights into the decision making of advisory groups to the Italian Medicines Agency. Ther. Innov. Reg. Sci. 48, 696-701

33 Mol, P.G. et al. (2015) Understanding drug preferences, different perspectives. Br. I. Clin. Pharmacol. 79, 978-987

34 Tafuri, G. et al. (2014) How do the EMA and FDA decide which anticancer drugs make it to the market? A comparative qualitative study on decision makers' views Ann. Oncol. 25, 265-269

35 Beyer, A.R. et al. (2015) Attitudes and personality traits predict perceptions of benefits and risks for medicinal products: a field study of European medical assessors. Value Health 18, 91-99

36 Bujar, M. et al. (2016) The impact of the evolving regulatory environment on the approval of new medicines across six major authorities 2006-2015 R\&D Briefing 59 Centre for Innovation in Regulatory Science.

37 Committee for Medicinal Products for Human Use (CHMP) European Medicines Agency (2016) CHMP withdrawal assessment report Begedina (begelomab).

38 Bujar, M. et al. (2016) Quality of regulatory decision-making practices: Issues facing companies and agencies. Ther. Innov. Reg. Sci. 50http://dx.doi.org/10.1177/ 2168479016628573

39 Pignatti, F. et al. (2015) Structured frameworks to increase the transparency of the assessment of benefits and risks of medicines: current status and possible future directions. Clin. Pharmacol. Ther. 98, 522-533

40 Leong, J. et al. (2013) Is there a need for a universal benefit-risk assessment framework for medicines? Regulatory and industry perspectives. Pharmacoepidemiol. Drug Saf. 22, 1004-1012 